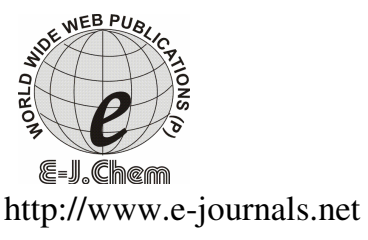

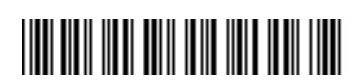

ISSN: 0973-4945; CODEN ECJHAO

E-Journal of Chemistry

Vol. 3, No.3, pp 110-116, July 2006

\title{
Synthesis, Characterization and Antimicrobial Activity of 5-(4-Methyl piperazinyl methylene)-8-hydroxy quinoline and its Various Metal Chelates
}

\author{
I. J. PATEL ${ }^{*}$ and I. M. VOHRA \\ P. T. Science Sarvajanic College, \\ Surat, Gujarat, INDIA.
}

Received 25 December 2005; Accepted 5 May 2006

\begin{abstract}
Chloromethyl-8-quinolinol was condensed with 4-methyl piperazine in presence of sodium bicarbonate. The resulting 5-(4-methyl piperazinylmethylene)-8-quinolinol (MPQ) was characterized by elemental analysis and spectral studies. The transition metal chelates viz $\mathrm{Cu}^{+2}, \mathrm{Ni}^{+2}, \mathrm{Co}^{+2}, \mathrm{Mn}^{+2}, \mathrm{Zn}^{+2}$, $\mathrm{Cd}^{+2}$, and $\mathrm{Fe}^{+3}$ of MPQ were prepared and characterized by metal-ligand (M:L) ratio, IR and reflectance spectroscopies and magnetic properties. The antifungal activity of MPQ and its metal chelates was screened against various fungi. The results show that all these samples are good antifungal agents.
\end{abstract}

Key words: 8-Hydroxy quinoline, IR and reflectance spectroscopies, metal chelates, magnetic moment, and antifungal properties.

\section{Introduction}

8-Hydroxyquinoline or 8-quinolinol is well known as an analytical reagent. ${ }^{1,2}$ It's various derivatives ${ }^{3}$ are also useful in pharmaceuticals. Several azo dyes based on 8-quinolinol are also reported for dyeing of textiles as well as their chelating properties. ${ }^{4,5}$ One based on the derivative say through replacement of chloro group of 5-chloromethyl-8-quinolinol (CMQ) can be synthesize easily. Various derivatives based on CMQ have also been reported in literature. ${ }^{5}$ The literature survey reveals that the reaction of CMQ with 4-substituted piperazine derivatives has not been reported so far. Hence it was thought to undertake such study. The present paper deals with synthesis, characterization and chelating properties of 5(4-methyl piperazinyl methylene)-8-quinolinol (MPQ) as Scheme-1. 


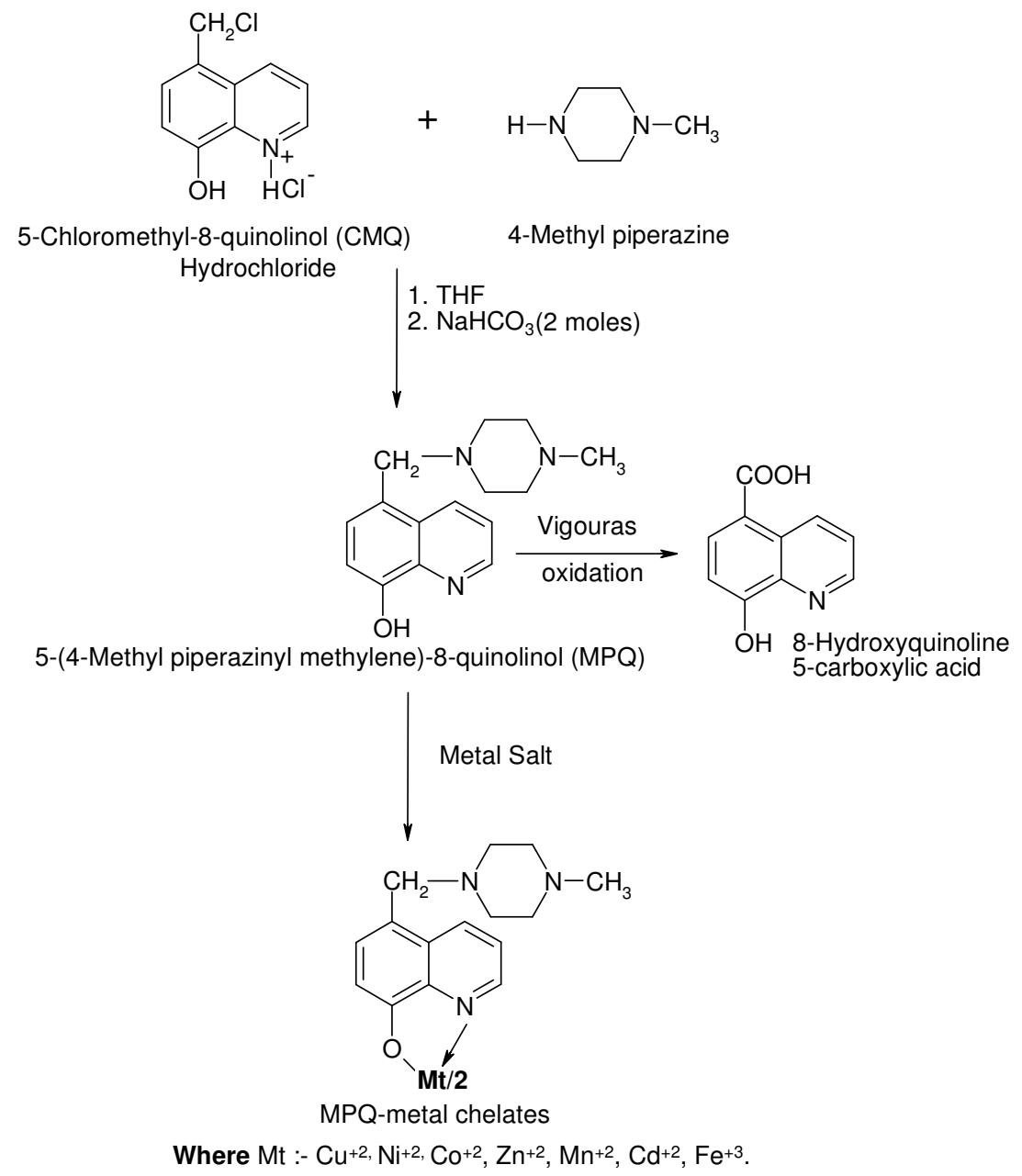

\section{Experimental}

Scheme -1

5-Chloromethyl-8-quinolinol (CMQ) hydrochloride was prepared according to method reported in literature. ${ }^{5} 8$-Quinolinol and 4-methyl piperazine were used as pure grade. All other chemicals used were of laboratory grade.

Synthesis of 5-(4-methyl piperazinyl methyl) -8- quinolinol: Formation of $M P Q$

In a round bottom flask, to a suspension of 5-chloromethyl-8-quinolinol (CMQ) hydrochloride (23 g, 0.1 mole) in tetrahydrofuran $(100 \mathrm{ml}$.), 4-methyl piperazine $(10.0 \mathrm{~g}, 0.1 \mathrm{~mole})$ was added gradually at room temperature. Sodium bicarbonate $(16.8 \mathrm{~g})$ was added in the mixture and the mixture was refluxed on water bath for three hours. The resulting solid mass was filtered off, washed with boiling water and then air-dried. It was dark green amorphous powder. It was insoluble in common organic solvent but soluble only in formic acid and DMSO. It did not melt upto $230^{\circ} \mathrm{C}$. The elemental analysis of MPQ is given in Table 1. 
Table 1. Analysis of MPQ Ligand and Its' Metal Chelates

\begin{tabular}{|c|c|c|c|c|c|c|c|c|c|c|c|}
\hline \multirow{3}{*}{$\begin{array}{l}\text { Ligand/metal } \\
\text { chelate }\end{array}$} & \multirow{3}{*}{ Molecular Formula } & \multirow{3}{*}{$\begin{array}{l}\text { Mol. } \\
\text { Wt. }\end{array}$} & \multirow{3}{*}{$\begin{array}{c}\% \\
\text { Yield }\end{array}$} & \multicolumn{6}{|c|}{ Elemental analysis } & \multirow{2}{*}{\multicolumn{2}{|c|}{ Metal }} \\
\hline & & & & \multicolumn{2}{|c|}{$\mathrm{C}$} & \multicolumn{2}{|c|}{$\mathrm{H}$} & \multicolumn{2}{|c|}{$\mathrm{N}$} & & \\
\hline & & & & Calc. & Found & Calc. & Found & Calc. & Found & calc. & Found \\
\hline MPQ liquid & $\mathrm{C}_{15} \mathrm{H}_{19} \mathrm{~N}_{3} \mathrm{O}$ & 257 & 80 & 70.03 & 69.8 & 7.39 & 7.3 & 16.34 & 16.2 & - & - \\
\hline $\mathrm{MPQ}-\mathrm{Cu}^{+2}$ & $\mathrm{C}_{30} \mathrm{H}_{36} \mathrm{~N}_{6} \mathrm{O}_{2} \cdot \mathrm{Ou}^{+2} \cdot 2 \mathrm{H}_{2} \mathrm{O}$ & 611.54 & 70 & 58.56 & 58.4 & 6.54 & 6.4 & 13.73 & 13.7 & 10.39 & 10.3 \\
\hline MPQ $-\mathrm{Ni}^{+2}$ & $\mathrm{C}_{30} \mathrm{H}_{36} \mathrm{~N}_{6} \mathrm{O}_{2} \cdot \mathrm{Ni}^{+2} \cdot 2 \mathrm{H}_{2} \mathrm{O}$ & 606.69 & 75 & 59.33 & 59.2 & 6.59 & 6.2 & 13.84 & 13.8 & 9.97 & 9.65 \\
\hline MPQ $-\mathrm{Co}^{+2}$ & $\mathrm{C}_{30} \mathrm{H}_{36} \mathrm{~N}_{6} \mathrm{O}_{2} \cdot \mathrm{CO}^{+2} \cdot 2 \mathrm{H}_{2} \mathrm{O}$ & 606.93 & 70 & 59.31 & 59.3 & 6.59 & 6.5 & 13.84 & 13.8 & 9.7 & 9.7 \\
\hline MPQ - $\mathrm{Mn}^{+2}$ & $\mathrm{C}_{30} \mathrm{H}_{36} \mathrm{~N}_{6} \mathrm{O}_{2} \cdot \mathrm{Mn}^{+2} \cdot 2 \mathrm{H}_{2} \mathrm{O}$ & 602.98 & 70 & 59.7 & 59.7 & 6.63 & 6.5 & 13.93 & 13.7 & 9.11 & 9 \\
\hline $\mathrm{MPQ}-\mathrm{Zn}^{+2}$ & $\mathrm{C}_{30} \mathrm{H}_{36} \mathrm{~N}_{6} \mathrm{O}_{2} \cdot \mathrm{Zn}^{+2} \cdot 2 \mathrm{H}_{2} \mathrm{O}$ & 613.28 & 65 & 58.7 & 58.7 & 6.32 & 6.2 & 13.69 & 13.6 & 10.66 & 10.6 \\
\hline $\mathrm{MPQ}-\mathrm{Cd}^{+2}$ & $\mathrm{C}_{30} \mathrm{H}_{36} \mathrm{~N}_{6} \mathrm{O}_{2} \cdot \mathrm{Cd}^{+2} \cdot 2 \mathrm{H}_{2} \mathrm{O}$ & 660.54 & 70 & 54.5 & 54.4 & 6.05 & 6 & 12.71 & 12.6 & 17.01 & 17 \\
\hline MPQ $-\mathrm{Fe}^{+3}$ & $\mathrm{C}_{30} \mathrm{H}_{36} \mathrm{~N}_{6} \mathrm{O}_{2} \cdot \mathrm{Fe}^{+3} \cdot 3 \mathrm{H}_{2} \mathrm{O}$ & 877.84 & 65 & 61.51 & 61.4 & 7.51 & 7.5 & 19.35 & 19.3 & 6.36 & 6.3 \\
\hline
\end{tabular}




\section{Synthesis of metal chelate of $M P Q$}

The metal chelates of MPQ were prepared in two steps. All the metal chelates were prepared in an identical procedure. The details are given in Table 1.

\section{Preparation of MPQ solution}

MPQ (15.7 g, 0.1 mole) was taken in 500-ml beaker. Formic acid was added until slurry formation. To this slurry, water was added till the complete dissolution of MPQ. Then it was diluted to $100 \mathrm{ml}$. This was the stock solution of MPQ.

\section{Formation of $M P Q$-metal chelates}

In a solution of metal acetate $(0.01 \mathrm{~mole})$ in acetone: water $(50: 50 \mathrm{v} / \mathrm{v})$ mixture $(40 \mathrm{ml})$, the $20 \mathrm{ml}$ of above mentioned MPQ stock solution (i.e. containing 0.02 M MPQ) was added with vigorous stirring at room temperature. The appropriate $\mathrm{pH}$ (Table 1) was adjusted by addition of sodium acetate for complete precipitation of metal chelate. The precipitates were digested on a boiling water bath. The precipitates of chelate were filtered off, washed by water and air-dried.

The details of all chelates are presented in Table-1.

\section{Measurements}

The elemental contents of $\mathrm{C}, \mathrm{H}, \mathrm{N}$ were determind by Thermoanalyser, Italy. The metals were determined volumetrically by Vogel's method. ${ }^{1}$ To a $100 \mathrm{mg}$ chelate sample, each $1 \mathrm{ml}$ of analar $\mathrm{HCl}, \mathrm{H}_{2} \mathrm{SO}_{4}$ and $\mathrm{HClO}_{4}$ were added and then $1 \mathrm{gm}$ of $\mathrm{NaClO}_{4}$ was added. The mixture was evaporated to dryness and the resulting salt was dissolved in double distilled water and diluted to the mark. From this solution the metal content was determined by titration with standard EDTA solution. Infrared spectra of the MPQ ligand and its metal chelate were recorded on Nicolet 760 FT-IR spectrometers. NMR spectrum of MPQ was recorded on $60 \mathrm{MHz}$ NMR spectrophotometer. Magnetic susceptibility measurement of the synthesized complexes was carried out on Gauy balance at room temperature. The electronic spectra of complexes in solid were recorded on at room temperature. $\mathrm{MgO}$ was used as reference. Antifungal activity of all the samples was monitored against various fungi, following the method reported in literature. ${ }^{6}$

\section{Results and Discussion}

The synthesis of 5-(4-methyl piperazinyl methylene)-8- quinolinol (MPQ) was performed by a simple nucleophilic substitution reaction of 4-methyl piperazine and 5-chloromethyl-8quinolinol hydrochloride (CMQ). The resulted MPQ ligand was an amorphous dark green powder. The $\mathrm{C}, \mathrm{H}, \mathrm{N}$ contents of MPQ (Table-1) are consistent with the structure predicted (scheme-1). The IR spectrum of MPQ comprises the important bands due to 8-quinolinol. These bands were observed at. 1630, 1575, 1500 and $1470 \mathrm{~cm}^{-1}$.

The broad band due to $\mathrm{OH}$ group appeared at $3800-2700 \mathrm{~cm}^{-1}$. In this band the inflections are observed at 2950, 2920 and $2850 \mathrm{~cm}^{-1}$. The first one may arise from $-\mathrm{CH}_{3}$ group. While the latter two might be attributed to asymmetric and symmetric vibrations of $\mathrm{CH}_{2}$ of piperazine moiety as well as from CMQ portion. The NMR spectrum of MPQ in DMSO indicates that the singlet at $2.30 \delta$ due to $8 \mathrm{H}$ of four $\mathrm{CH}_{2}$ groups. The Singlet of $4 \mathrm{H}$ at $2.6 \delta$ of $\mathrm{N}_{-} \mathrm{CH}_{2}-\mathrm{Ar}$ group. The singlet of $3 \mathrm{H}$ of $\mathrm{CH}_{3}$ group at $3.2 \delta$, the Singlet at $2.8 \delta$ is of $-\mathrm{OH}$ group. The aromatic protons are appeared in multiplicity at $7.2 \delta$. The vigorous 
oxidation of MPQ yield 8-hydroxy quinoline-5-carboxylic acid m.p: - $230{ }^{\circ} \mathrm{C}$ (dec). ${ }^{7}$ Thus the structure of MPQ is confirmed as shown in Scheme-1.

The C, H, N contents of metal chelates of MPQ (Table 1) are also consistent with the predicted structure (Scheme 1). The metal content of each chelate is shown in Table 1. The results show that the metal: ligand $(\mathrm{M}: \mathrm{L})$ ratio for all chelate except test is $1: 2$. The $\mathrm{Fe}^{+3}$ chelate was found to be the $\mathrm{M}: \mathrm{L}$ ratio is $1: 3$.

The infrared spectra of all the chelates are identical and suggest the formation of all the metalocyclic compound by the absence of band characteristic of free $\mathrm{OH}$ group of parent MPQ. The other bands are almost at their respectable positions as appeared in the spectrum of parent-MPQ ligand. However the band due to M-O band could not be detected as it may appeared below the range of instrument used. The important IR spectral data are shown in Table 2 .

Table 2. Spectral Features and Magnetic Moment of MPQ - Metal Chelates.

\begin{tabular}{|c|c|c|c|c|c|}
\hline $\begin{array}{c}\text { Metal } \\
\text { Chelates }\end{array}$ & $\begin{array}{l}{ }^{\mu} \text { eff } \\
\text { BM }\end{array}$ & $\begin{array}{c}\text { Electronic } \\
\text { spectral Data } \\
\mathrm{Cm}^{-1}\end{array}$ & Transition & \multicolumn{2}{|c|}{$\begin{array}{l}\text { IR spectral features } \\
\text { common for all } \\
\mathrm{Cm}^{-1}\end{array}$} \\
\hline MPQ $-\mathrm{Cu}^{+2}$ & 2.10 & $\begin{array}{l}23250 \\
15875\end{array}$ & $\begin{array}{l}\text { Chargetranster } \\
2 \mathrm{~B}_{1 \mathrm{~g}} \rightarrow 2 \mathrm{~A}_{1 \mathrm{~g}}\end{array}$ & $\begin{array}{l}1650 \\
1565 \\
1500 \\
1460\end{array}$ & $\begin{array}{l}\text { Quinoline } \\
\text { moeity }\end{array}$ \\
\hline MPQ $-\mathrm{Ni}^{+2}$ & 3.36 & $\begin{array}{l}22580 \\
15375\end{array}$ & $\begin{aligned} 3 \mathrm{~A}_{1 \mathrm{~g}} & \rightarrow 3 \mathrm{~T}_{1 \mathrm{~g}}(\mathrm{P}) \\
3 \mathrm{~A}_{1 \mathrm{~g}} & \rightarrow 3 \mathrm{~T}_{1 \mathrm{~g}}(\mathrm{~F})\end{aligned}$ & $\begin{array}{l}2920 \\
2850\end{array}$ & $\mathrm{CH}_{2}$ \\
\hline MPQ $-\mathrm{Co}^{+2}$ & 4.60 & $\begin{array}{c}22724 \\
15260 \\
8935\end{array}$ & $\begin{array}{l}4 \mathrm{~T}_{1 \mathrm{~g}}(\mathrm{~F}) \rightarrow 4 \mathrm{~T}_{2 \mathrm{~g}}(\mathrm{~F}) \\
4 \mathrm{~T}_{1 \mathrm{~g}}(\mathrm{~F}) \rightarrow 4 \mathrm{~T}_{2 \mathrm{~g}} \\
4 \mathrm{~T}_{1 \mathrm{~g}}(\mathrm{~F}) \rightarrow 4 \mathrm{~T}_{2 \mathrm{~g}}(\mathrm{P})\end{array}$ & $\begin{array}{c}2970,13 \\
70 \\
1100 \\
500\end{array}$ & $\begin{array}{l}\mathrm{CH}_{3} \\
\mathrm{C}-\mathrm{O}-\mathrm{M} \& \\
\mathrm{O}-\mathrm{M} \text { bands }\end{array}$ \\
\hline MPQ $-\mathrm{Mn}^{+2}$ & 5.48 & $\begin{array}{l}23860 \\
18345 \\
16820\end{array}$ & $\begin{array}{l}6 \mathrm{~A}_{1 \mathrm{~g}} \rightarrow 4 \mathrm{~A}_{2 \mathrm{~g}} 4 \mathrm{E}_{\mathrm{g}} \\
6 \mathrm{~A}_{1 \mathrm{~g}} \rightarrow 4 \mathrm{~T}_{2 \mathrm{~g}}(4 \mathrm{G}) \\
6 \mathrm{~A}_{1 \mathrm{~g}} \rightarrow 4 \mathrm{~T}_{1 \mathrm{~g}}(\mathrm{PG})\end{array}$ & - & - \\
\hline MPQ $-\mathrm{Zn}^{+2}$ & - & Diamagnetic & & - & - \\
\hline $\mathrm{MPQ}-\mathrm{Cd}^{+2}$ & - & Diamagnetic & & & \\
\hline $\mathrm{MPQ}-\mathrm{Fe}^{+3}$ & - & $\begin{array}{l}22839 \\
18895\end{array}$ & $\begin{array}{l}6 \mathrm{~A}_{1} \rightarrow 4 \mathrm{~T}_{2}(4 \mathrm{G}) \\
6 \mathrm{~A}_{1} \rightarrow 4 \mathrm{~A}_{1}(4 \mathrm{G})\end{array}$ & & \\
\hline
\end{tabular}

Magnetic moments of metal chelates are given in Table-2. The diffuse electronic spectrum of the $\mathrm{Cu}^{+2}$ chelate shows two broad bands around 13000 and $23000 \mathrm{~cm}^{-1}$. The first band may be due to $\mathrm{a}^{2} \mathrm{~T}_{2 \mathrm{~g} \otimes} \cdot{ }^{2} \mathrm{E}_{\mathrm{g}}$ transition, while the second band may be due to charge transfer. The first band shows structures suggesting a distorted octahedral structure for the $\mathrm{Cu}^{+2}$ metal chelate. ${ }^{8,9}$ 
Table 3. Antifungal Activity of MPQ Ligand and Its Metal Chelates

\begin{tabular}{cccccccc}
\hline & \multicolumn{7}{c}{ Zone of inhibition of fungas at 1000 ppm (\%) } \\
\cline { 2 - 8 } Sample & $\begin{array}{c}\text { Penicillium } \\
\text { Expansum }\end{array}$ & $\begin{array}{c}\text { Botrydepladia } \\
\text { thiobromine }\end{array}$ & $\begin{array}{c}\text { Nigrospara } \\
\text { sp. }\end{array}$ & $\begin{array}{c}\text { Trichothes } \\
\text { ium sp. }\end{array}$ & $\begin{array}{c}\text { Rhizopus } \\
\text { Nigricans }\end{array}$ & $\begin{array}{c}\text { Aspergillus } \\
\text { niger }\end{array}$ & $\begin{array}{c}\text { Trichoder } \\
\text { ma } \\
\text { Lignorum }\end{array}$ \\
\hline MPQ & 55 & 54 & 53 & 63 & 63 & 67 & 70 \\
MPQ - Cu & 83 & 78 & 77 & 83 & 81 & 84 & 85 \\
MPQ - $\mathrm{Zn}^{+2}$ & 75 & 64 & 63 & 77 & 83 & 83 & 84 \\
MPQ - Ni & 80 & 77 & 75 & 75 & 73 & 81 & 80 \\
MPQ - Co & 65 & 76 & 75 & 73 & 78 & 79 & 85 \\
MPQ - $\mathrm{Mn}^{+2}$ & 79 & 75 & 73 & 75 & 80 & 77 & 83 \\
MPQ - $\mathrm{Cd}^{+2}$ & 80 & 85 & 89 & 80 & 85 & 75 & 85 \\
MPQ - $\mathrm{Fe}^{+3}$ & 65 & 60 & 70 & 65 & 70 & 65 & 60
\end{tabular}


The higher value of the magnetic moment of the $\mathrm{Cu}^{+2}$ chelate supports the same. The $\mathrm{Co}^{+2}$ metal chelate gives rise to two absorption bands at 23800 and $19040 \mathrm{~cm}^{-1}$, which can be assigned to, ${ }^{4} \mathrm{~T}_{1 \mathrm{~g} \circledast} \cdot{ }^{2} \mathrm{~T}_{2 \mathrm{~g},},{ }^{4} \mathrm{~T}_{1 \mathrm{~g} \circledast} \cdot{ }^{4} \mathrm{~T}_{1 \mathrm{~g}}(\mathrm{P})$ transitions. ${ }^{10,11}$ These absorption bands and the $\mu_{\text {eff value }}$ indicate an octahedral configuration of the $\mathrm{Co}^{+2}$ metal chelate. ${ }^{10,11}$ The spectrum of $\mathrm{Mn}^{+2}$ polymeric chelate comprised two bands at $19010 \mathrm{~cm}^{-1}$ (asymm.) and $23300 \mathrm{~cm}^{-1}$. The latter does not have a very long tail. These bands may be assigned to ${ }^{6} \mathrm{~A}_{1 \circledast}{ }^{4} \mathrm{~T}_{2}(\mathrm{G})$ and ${ }^{6} \mathrm{~A}_{1 \circledast},{ }^{4} \mathrm{~A}_{1}(\mathrm{G})$ transitions, respectively. The high intensity of the bands suggests that they may have some charge transfer character. The magnetic moment is found to be lower than normal range. In the absence of low temperature measurement of magnetic moment it is difficult to attach any significance to this. As the spectrum of the metal chelate of $\mathrm{Ni}^{+2}$. Show two distinct bands at $11960-11450 \mathrm{~cm}^{-1}$ and $17700-17400 \mathrm{~cm}^{-1}$. Which are assigned as $3 \mathrm{~A}_{2 \mathrm{~g}}(\mathrm{~F})->$ $3 \mathrm{~T}_{1 \mathrm{~g}}(\mathrm{~F})$ and $3 \mathrm{~A}_{2 \mathrm{~g}}(\mathrm{~F})->3 \mathrm{~T}_{1 \mathrm{~g}}(\mathrm{~F})$ transity respectively. Suggestily and octahydrly environment $\mathrm{Ni}^{+2}$ ion. The observed $\mu_{\text {eff }}$ values in the range 3.01 to 3.2 B.M. are consistent with the above moiety. ${ }^{8,12}$

The examination of antifungal activity of MPQ ligand and its all chelates (Table-3) reveals that the ligand is moderately toxic against fungi. While all the chelates are more toxic than ligand. Off all the chelates the $\mathrm{cu}^{+2}$ chelate is more toxic against fungi.

The spectrum of $\mathrm{Fe}^{+3}$ chelate show the two bands around 19000 and around $28000 \mathrm{~cm}^{-1}$. The later has very long fail. This may assign the ${ }^{6} \mathrm{~A}_{1}{ }^{4} \mathrm{~T}_{2}(4 \mathrm{G})$ as ${ }^{6} \mathrm{~A}_{1}{ }^{\bullet}{ }^{4} \mathrm{~A}_{1}$ (4G) transition. The magnetic moment is found to be lower than normal range. Hence it is difficult to predict the geometry of MPQ-Fe ${ }^{+3}$ chelate.

\section{References}

1. Vogel A I, A Textbook of Quantitative chemical analysis, Revised by Besselt J, Denny R C, Jeffery J H and Mendham J, ELBS, $5^{\text {th }}$ ed. London 1996.

2. Ivanor V M and Metkina T F, Zh. Anal. Khim, 1978, 33, 2426.

3. Burckhalter J H, Stephars V C, Searberough H C, Briniger W S and Edergton W E, J. Am. Chem. Soc., 1954, 76, 4902.

4. Vogel C and Heinz W, Brazil Pat. 1977, 78,05, 009; Ger. Pat. 1977, 2,832,758.

5. Burckhalter J H and Leib R, J. Org. Chem., 1961, 26, 4078.

6. Barry A L, The antimicrobial susceptibility Test: Principal, and Practice Lea \& Febiger Philadelphia, 1976.

7. Masumuru S, J. Am. Chem. Soc., 1931, 53,1494.

8. Lever A B P, Inorganic electronic spectroscopy, Elserier, N. Y. 1968.

9. Figgis B N and Lewis J, Prog. Inorg. Chum, 1969, 6, 97.

10. Satpathy K C, Pande A K, Mishra R and Miss I. Panda, Synth. React. Inorg. Met. Org. Chem. 1991, 21, 531.

11. Caroline R L and Van A J, Dryneveldt, Magnetic properties of Transition Metal compounds Springer-Verlag, N. Y. 1997.

12. Kettle F A, Coordination Compounds, Thomas Nelson and Sons, 1975. 


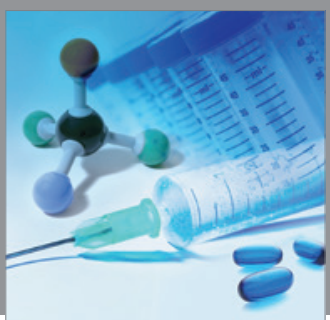

International Journal of

Medicinal Chemistry

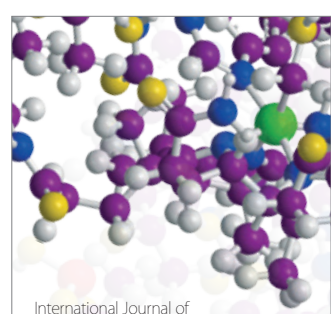

Carbohydrate Chemistry

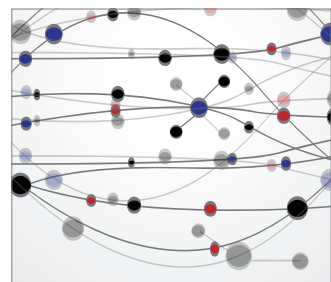

The Scientific World Journal
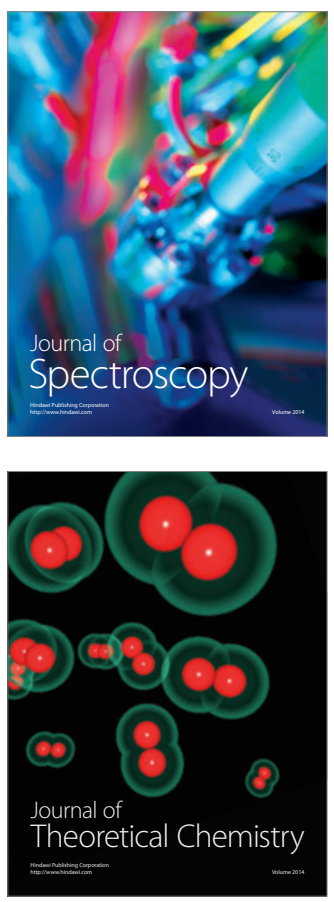
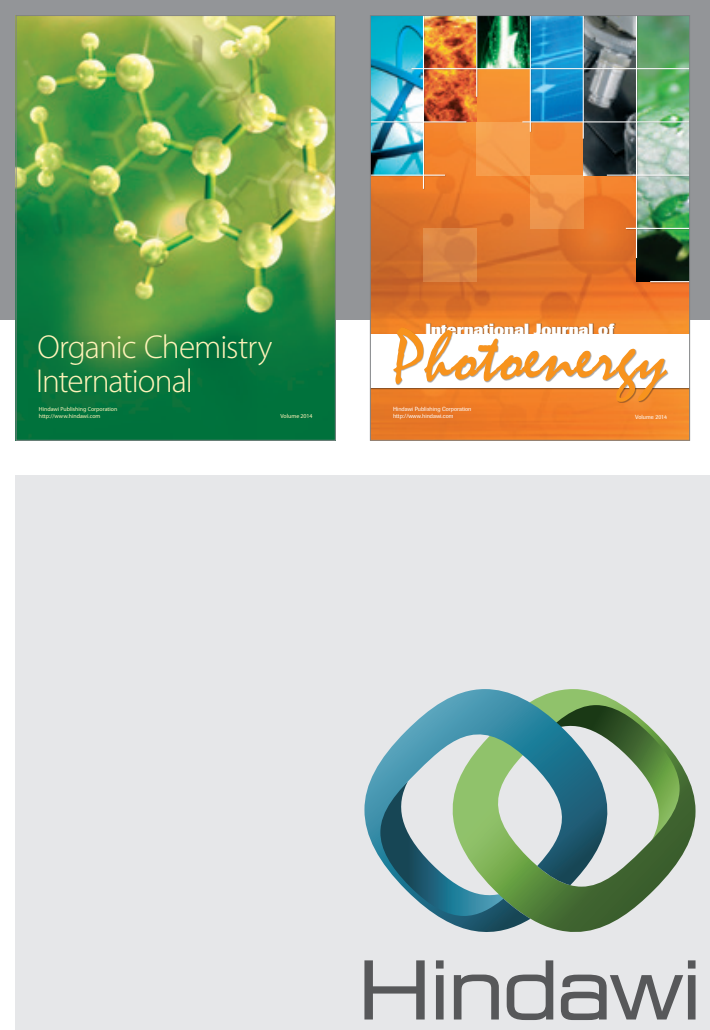

Submit your manuscripts at

http://www.hindawi.com
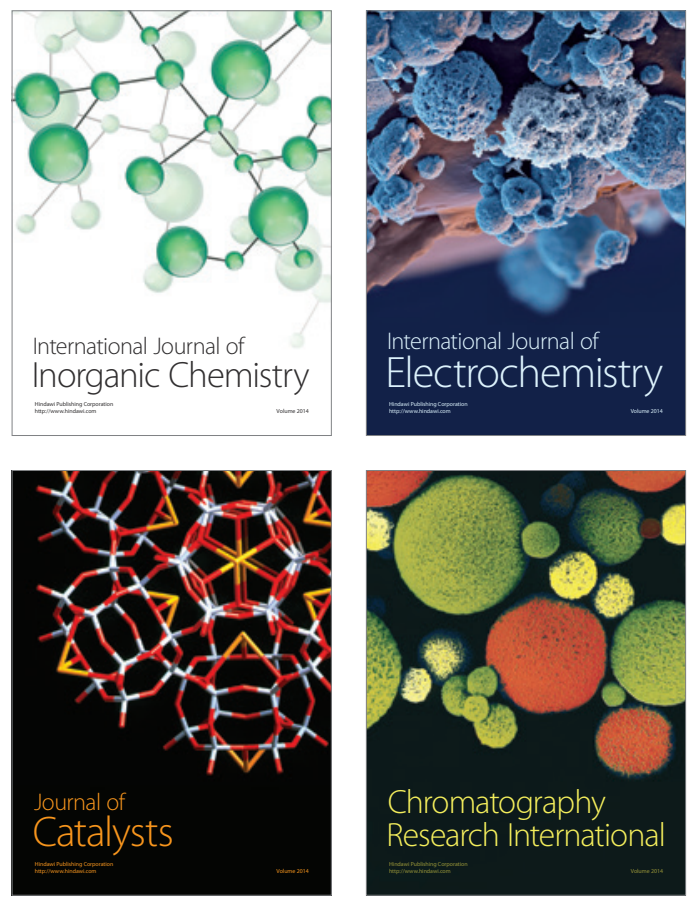
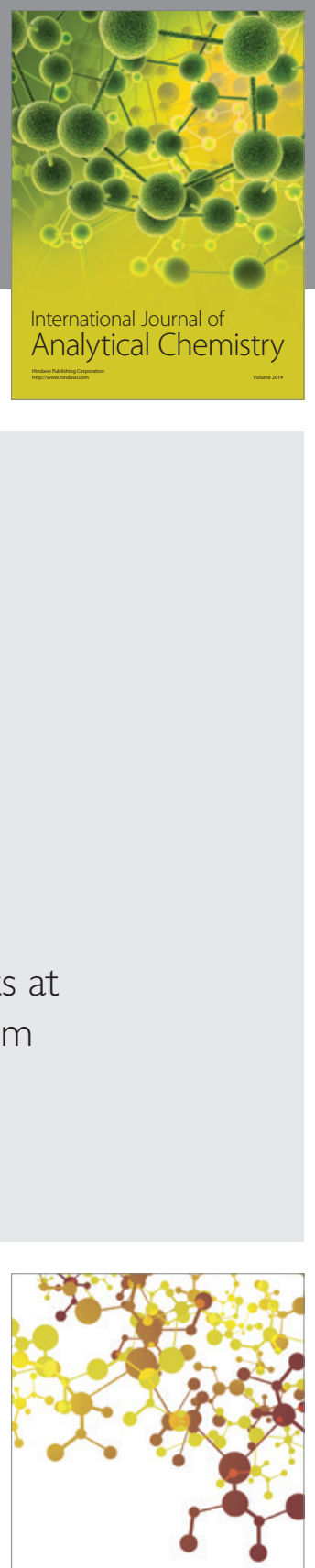

Journal of

Applied Chemistry
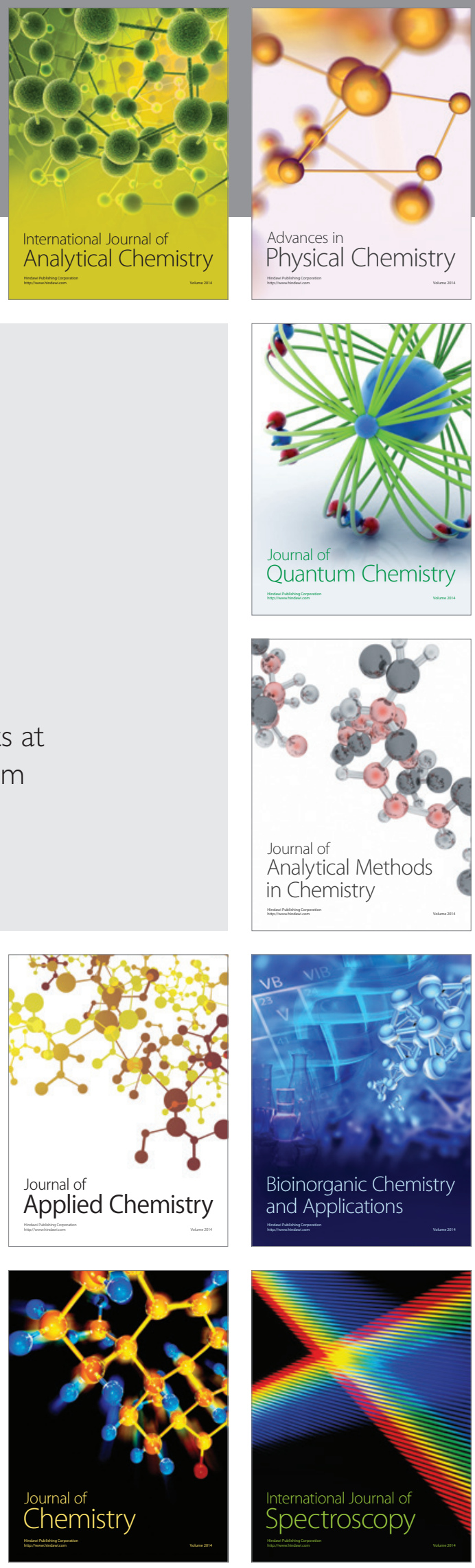